\title{
Coastal Ecosystems and Tsunami Protection after the December 2004 Indian Ocean Tsunami
}

\author{
Stephanie E. Chang, ${ }^{\text {a) }}$ M.EERI, Beverley J. Adams, ${ }^{\text {b) }}$ Jacqueline Alder, ${ }^{\text {) }}$ \\ Philip R. Berke, ${ }^{\text {d) }}$ Ratana Chuenpagdee, ${ }^{\text {e) }}$ Shubharoop Ghosh, \\ and Colette Wabnitz ${ }^{\mathrm{c})}$
}

An exploratory study was conducted on the role of coastal ecosystems in protecting communities from the December 2004 Indian Ocean tsunami, focusing on mangrove forests on the Andaman coast of Thailand and how well villages were undertaking environmental conservation. Remote sensing analysis identified predisaster mangrove change and postdisaster structural damage and landscape changes. Field data from five sites (20 villages), gathered via the VIEWS ${ }^{\mathrm{TM}}$ data collection system, validated and supplemented this analysis. Key informants at several of these villages were also interviewed. A preliminary comparison of villages that otherwise faced similar tsunami exposure suggests that the presence of healthy mangroves did afford substantial protection. Village performance in mangrove conservation and management efforts, and thus the presence of healthy forests, is influenced by both social capital and the design of external aid delivery programs.

[DOI: 10.1193/1.2201971]

\section{INTRODUCTION}

The December 2004 Indian Ocean tsunami disaster has generated much attention to such preparedness measures as early warning systems, the design of tsunami-resistant structures, and evacuation planning. Yet important lessons can also be learned about another, often-overlooked strategy of hazard mitigation - environmental conservation. Can environmental conservation provide some degree of protection from natural hazards? How well are communities undertaking such conservation? Did degradation of coastal ecosystems before the 2004 tsunami and poor environmental management serve to exacerbate communities' vulnerability?

\footnotetext{
a) School of Community and Regional Planning, University of British Columbia, 242-1933 West Mall,

Vancouver, British Columbia V6T 1Z2, Canada

b) ImageCat Inc., European Operations, 246 Barnett Wood Lane, Ashtead, Surrey, KT21 2BY, UK

c) Fisheries Centre, University of British Columbia, 2202 Main Mall, Vancouver, British Columbia V6T 1Z4, Canada

d) Department of City and Regional Planning, and Carolina Environmental Program, University of North Carolina, Chapel Hill, NC 27599-3140

e) International Ocean Institute, Dalhousie University, 1226 LeMarchant Street, Halifax, Nova Scotia B3H 3P7, Canada

f) ImageCat Inc., 400 Oceangate, Suite 1050, Long Beach, CA 90802
} 


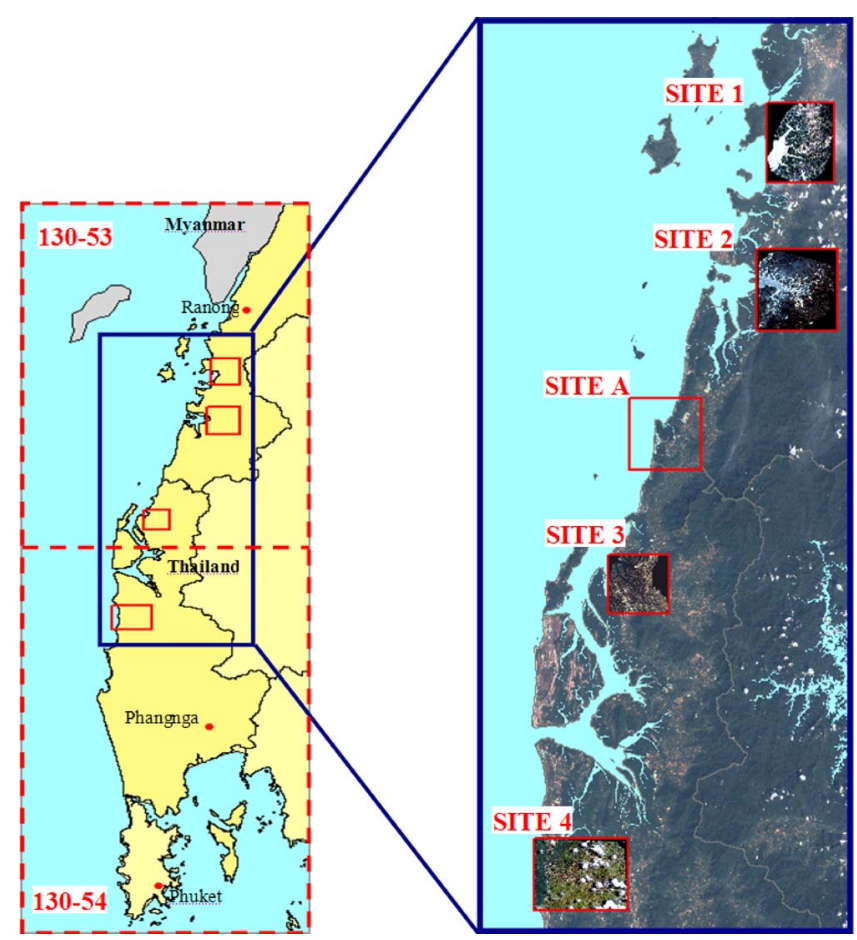

Figure 1. Study area and sites.

In addressing such issues, this preliminary study focuses on the case of mangroves on the northern Andaman coast of Thailand (Figure 1). Mangroves are trees and associated shrubs found in intertidal zones and estuarine margins that have adapted to living in seawater, either continually or during high tides. Found throughout the tropics, mangroves provide many important ecosystem functions, including protecting land from the open ocean. Characterized by tangled root structures and flexible branches, they buffer wave activity, thereby limiting both coastal erosion and storm damage. Although mangroves can buffer the impact of waves, including tsunamis, they do not necessarily prevent loss of life. For example, in the 1998 Papua New Guinea tsunami, the waves sheared mangroves off to a height of $1-2 \mathrm{~m}$, resulting in a number of fatalities and injuries (Dengler and Preuss 1998); we have not, however, found evidence of this occurring in Thailand in the 2004 tsunami. Many mangrove areas have become degraded worldwide, and habitat conversion of mangroves is widespread. In some countries, more than $80 \%$ of the original mangrove cover has been lost. In many tropical regions, an important cause of such loss is the aquaculture industry, typically through conversion of mangrove wetlands to shrimp or prawn farms; other causes include clear-cutting for charcoal production or coastal development. In the islands of Indonesia, Java alone had lost $70 \%$ of its mangroves by 1991, while Sulawesi had lost $49 \%$, and Sumatra had lost 36\% (www.earthisland.org). In Thailand, mangroves previously covered some 
COASTAL ECOSYSTEMS AND TSUNAMI PROTECTION AFTER THE DECEMBER 2004 INDIAN OCEAN TSUNAMIS865

$3,680 \mathrm{~km}^{2}$ in 1961 , declining to only 2,400 in $\mathrm{km}^{2}$ by 2002 . More recently, however, increased awareness in Thailand has led to significant efforts to preserve and restore mangroves (Fast and Menasveta 2003).

Previous studies provide limited evidence of the effectiveness of mangroves in buffering tsunami waves, for example, through engineering experiments or modeling studies (e.g., Harada and Imamura 2003, Hiraishi and Harada 2003) and through descriptive comparative accounts of coastal impacts of storms in areas with and without mangroves. Observations of mangrove buffering capacity in the 2004 Indian Ocean tsunami have been reported anecdotally in initial press accounts and more recently in regional and scientific reports (e.g., Dahdouh-Guebas et al. 2005; FAO 2005; Wetlands International $2005 \mathrm{a}, \mathrm{b})$. However, because onshore tsunami forces are heavily influenced by numerous factors, including local bathymetry, topography, coastline orientation, and offshore islands (Synolakis 2002), a more definitive test of the buffering capacity of mangroves requires a more systematic analysis.

In this preliminary study, we address the role of mangroves in tsunami protection from both a biophysical perspective and an environmental management one. We use data from satellite imagery as well as field observations and interviews. From a biophysical standpoint, our primary objective is to gain insight into the extent to which mangroves buffered coastal communities from the tsunami, and, in particular, whether predisaster clearing of mangroves may have exacerbated tsunami losses. This requires addressing many challenges, including identifying those areas that actually underwent predisaster mangrove clearing for aquaculture, charcoal, and other purposes; identifying and characterizing tsunami damage over a broad area by using remote sensing data; and isolating the role of mangrove clearing from other factors (such as wave exposure, bathymetry/ slope, and orientation) that are expected to also affect tsunami damage and loss.

From an environmental management perspective, our primary objective is to explore factors contributing to the protection that mangroves may or may not have provided, specifically (1) to determine the level of community performance (adoption of appropriation rules, adoption of governance rules, and monitoring) in the protection of mangroves; (2) to assess the level of local social capital and the design of external aid delivery programs (bottom-up versus top-down); and (3) to explore relationships among community performance, social capital, and external aid programs.

We integrate both the biophysical and management aspects of the problem by focusing our field work on a number of coastal villages in two provinces, Phang Nga and Ranong, along the northern Andaman coast of Thailand. In the 2004 tsunami, close to 5,000 people lost their lives in Thailand (UNEP 2005), some 4,300 of them in these two provinces (4,163 reported deaths in Phang Nga and 2,043 missing persons) (Wetlands International 2005b). This paper discusses the conceptual framework, methodological approach, and data collection for the study. It begins with the biophysical portion of the study, wherein remote sensing analysis is used to identify both predisaster mangrove conditions and postdisaster damage. It then describes the field work that was conducted to gather data to validate and supplement the remote sensing analysis. This is followed 


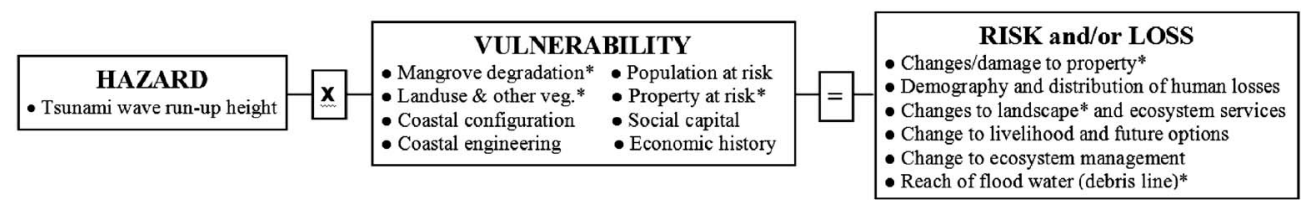

Figure 2. Conceptual framework. Asterisks denote parameters that were characterized in this study via remote sensing technology.

by discussion of the management portion of the study, which focused on gathering interview data in the field. We offer tentative observations based on preliminary analysis of our data.

\section{CONCEPTUAL FRAMEWORK}

We conceptualize loss, or risk, as arising from the interaction of the physical hazard (tsunami waves) and vulnerability (Figure 2). Vulnerability is influenced by a broad range of biophysical and socioeconomic factors, ranging from coastal configuration to mangrove status, settlement patterns, and social capital (features of social organization such as networks and trust that enable collective action). Risk or loss, in turn, can be measured along many dimensions - from the extent of inundation, erosion, and landscape modification by the tsunami to human casualties, property damage, and changes to livelihoods and environmental management.

Investigating the potential role of mangroves in tsunami protection therefore requires taking into account factors other than mangroves that influence loss, as well as the variety of ways in which loss can be characterized. Our general approach has been to isolate the effect of mangroves, to the extent possible, by identifying and comparing locations that are similar along all important dimensions except for mangrove status.

\section{SITE SELECTION}

Careful site selection was therefore essential. The process of selecting study sites involved a number of steps, and remote sensing technology played a key role in many of these steps. We focused on the northern Andaman coast of Thailand (Figure 1), where coastal configurations are less complex than further south, and where mangroves have had a historically and currently significant presence. We acquired moderate-resolution Landsat TM 5 data for this entire region and high-resolution satellite imagery for four selected sites within the region. Table 1 documents the remote sensing data acquired for this study.

Methodologies were developed to classify remote sensing imagery according to coastal land use types and to estimate mangrove change in our study area. The analysis of coastal land use employed pretsunami 7-band Landsat TM 5 imagery, spanning the Thailand coast northward from Phuket Island (Table 1). After a number of preprocessing steps, the images were classified by using ENVI software according to distinct land use types (for further details on this process, see the remote sensing data section of this pa- 
Table 1. Satellite imagery acquired for the study area

\begin{tabular}{|c|c|c|c|c|c|}
\hline \multirow[b]{2}{*}{ Landsat data } & \multirow[b]{2}{*}{$\begin{array}{l}\text { Field } \\
\text { site ID }\end{array}$} & \multicolumn{4}{|c|}{ High-resolution data } \\
\hline & & $\begin{array}{l}\text { High-resolution satellite/ } \\
\text { data provider }\end{array}$ & Date of acquisition & $\begin{array}{l}\text { Spatial } \\
\text { resolution }\end{array}$ & Data format \\
\hline \multirow{3}{*}{$\begin{array}{l}\text { Scene 130-53 } \\
\text { Historic: Landsat } 5 \text { 3-14-91 } \\
\text { Before: Landsat } 5 \text { 4-18-04 } \\
\text { After: Landsat } 5 \text { 12-30-04 }\end{array}$} & Site 1 & Quickbird/Digitalglobe & $\begin{array}{l}\text { Before: } 3-2-04 \\
\text { After: 3-28-05 }\end{array}$ & $60 \mathrm{~cm}$ & Pan-sharpened 3-band color \\
\hline & Site 2 & Quickbird/Digitalglobe & $\begin{array}{l}\text { Before: } 3-2-04 \\
\text { After: } 3-28-05\end{array}$ & $60 \mathrm{~cm}$ & Pan-sharpened 3-band color \\
\hline & Site 3 & IKONOS/Space Imaging & $\begin{array}{l}\text { Before: 2-23-01 } \\
\text { After: 2-06-05 }\end{array}$ & $1 \mathrm{~m}$ & Pan-sharpened 3-band color \\
\hline \multirow{3}{*}{$\begin{array}{l}\text { Scene 130-54 } \\
\text { Historic: Landsat } 5 \text { 3-14-91 } \\
\text { Before: Landsat } 5 \text { 4-18-04 } \\
\text { After: Landsat } 5 \text { 12-30-04 }\end{array}$} & \multirow{3}{*}{ Site 4} & IKONOS/Space Imaging & Before: 6-24-02 & $1 \mathrm{~m} / 4 \mathrm{~m}$ & $\begin{array}{l}\text { Registered 1-m Pan and 4-m } \\
\text { color bands }\end{array}$ \\
\hline & & IKONOS/Space Imaging & After: 1-1-05 & $1 \mathrm{~m} / 4 \mathrm{~m}$ & $\begin{array}{l}\text { Registered 1-m Pan and 4-m } \\
\text { color bands }\end{array}$ \\
\hline & & Quickbird/Digitalglobe & After: 1-2-05 & $80 \mathrm{~cm} / 2.4 \mathrm{~m}$ & $\begin{array}{l}\text { Nonregistered } 80-\mathrm{cm} \text { Pan and } \\
2.4-\mathrm{m} \text { color bands }\end{array}$ \\
\hline
\end{tabular}

${ }^{a}$ Includes sites 1-3

${ }^{\mathrm{b}}$ Includes site 4 


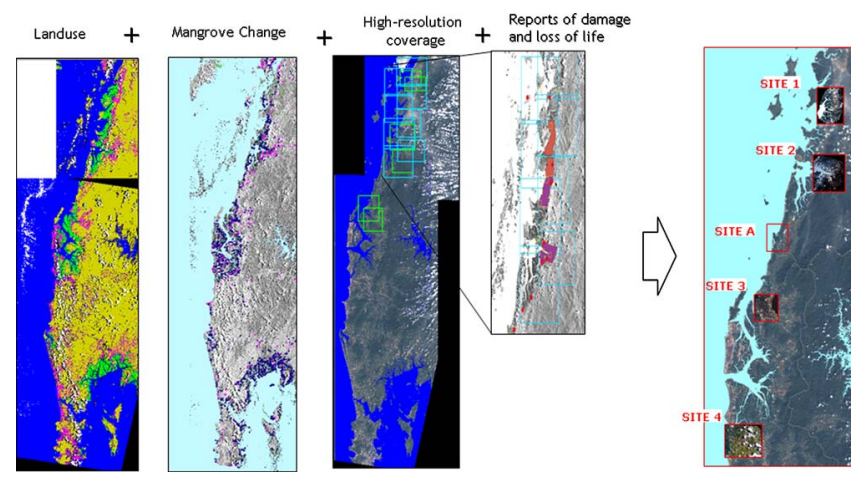

Figure 3. Site selection process, whereby we overlaid maps generated for land use and mangrove change with available high-resolution coverage and local reports of damage and loss of life. Ranong province is used here as an example.

per). An analysis of mangrove change using a historic Landsat TM 5 image acquired in March 1991 (courtesy of Thailand's Geo-informatics and Space Technology Development Agency, or GISTDA) was also carried out, highlighting (1) areas that historically were mangroves and have been converted to urban areas or aquaculture ponds and (2) areas that are now mangrove forests but were not in 1991. The final result was saved in GIS format (Arcview*. bil) and imported to Arcview 3.2 for detailed visual inspection and integration with other layers.

Once maps of land use classification and mangrove change were generated, these were overlaid in ArcView (Figure 3) with the following information:

- High-resolution imagery with minimal cloud coverage available for the area (Quickbird and IKONOS)

- Reports of damage to property and high loss of life obtained from Thai web sites (the red dots/solid dots in grayscale in Figure 3)

- Bathymetry details gleaned from nautical charts purchased from Tides End Ltd. (charts 63440 and 71040 - true reproductions of charts produced by the Defense Mapping Agency Hydrographic/Topographic Center and the National Imagery and Mapping Agency, respectively)

- Topographic maps of the two provinces provided by the Coastal Development Center at Kasetsart University in Bangkok

Within each site, "location pairs" were then selected. "Location pairs" were identified as communities with similar bathymetric details and coastline exposure but which were afforded potentially different protection levels by mangroves-i.e., one village of the location pair was behind the mangroves, whereas the other one was in front of the mangroves or in an area cleared of mangroves. Moreover, the site selection process also took the following information into consideration:

- Reports from NGO teams and others who had gone into the field and carried out 
COASTAL ECOSYSTEMS AND TSUNAMI PROTECTION AFTER THE DECEMBER 2004 INDIAN OCEAN TSUNAMIS869

rapid assessments of landscape changes or level of impact, or who had taken notes about the potential buffering capacity of mangrove forests (FAO 2005, Wetlands International 2005b)

- Tsunami runup heights recorded by two teams of Japanese researchers who visited sites along the northern Andaman coast shortly after the disaster (Research Group 2004)

Initially, we also sought to incorporate NOAA data on modeled tsunami wave heights (PMEL 2005). However, due to the lack of high-resolution data to capture the complex bathymetry along the Andaman coast (Titov 2005), the near-shore resolution of the model was insufficient for our purposes of making locally detailed comparisons.

Once the sites were selected, high-resolution imagery was purchased for each one (Table 1). During field deployment, the data collection protocol that was developed remained adaptive to take into account information provided by local researchers from the Coastal Development Centre and Ranong Coastal Resource Research Station. As a result of these exchanges, Site A (Figure 1) was added to our original four data collection sites.

\section{REMOTE SENSING DATA}

\section{PREDISASTER LAND USE AND MANGROVE CHANGE}

From Figure 2, coastal land use and mangrove change are key indicators of the predisaster condition. The remote sensing analysis of coastal land use employed pretsunami 7-band Landsat TM 5 images spanning the north Andaman coast (Table 1), which were provided courtesy of GISTDA. From a methodological standpoint, a sequence of preprocessing steps was initially performed on the data. Via image processing software, the data sets were reformatted as a "stacked" image and then registered to a historic MRSID Landsat Thematic Mapper (TM) composite (UTM, WGS84 zone 47N) obtained from the U.S. Geological Survey. Coastal land use was obtained by using maximum likelihood supervised classification. A set of input training regions was manually selected within each image for visually distinct land use classes of interest, comprising (1) mangrove, (2) edge of mangrove and mud flat, (3) aquaculture, (4) urban/rural/sand/cleared land, (5) other vegetation, (6) water, (7) cloud, and (8) shadow. The output classification image was subjected to a clumping filter in order to remove rogue outliers falling within otherwise homogenous classified regions. The final result was saved in GIS format for detailed visual inspection and integration with other layers. A quantitative accuracy assessment remains to be conducted.

For the analysis of mangrove change, the land use classification methodology was repeated for a historic TM 5 image acquired in March 1991. After classification, the classes "mangrove" and "edge of mangrove" were combined to yield a "master" mangrove class. The "historic" and "before" classification results were evaluated by using a change detection routine, whose output was a "change" image and statistics for each permutation of class change. The changes of interest (mangrove to urban, mangrove to aquaculture, and "other" classes to mangrove) shown in Figure 4 were then converted to a GIS-compatible format for visualization. 
(a)

(b)

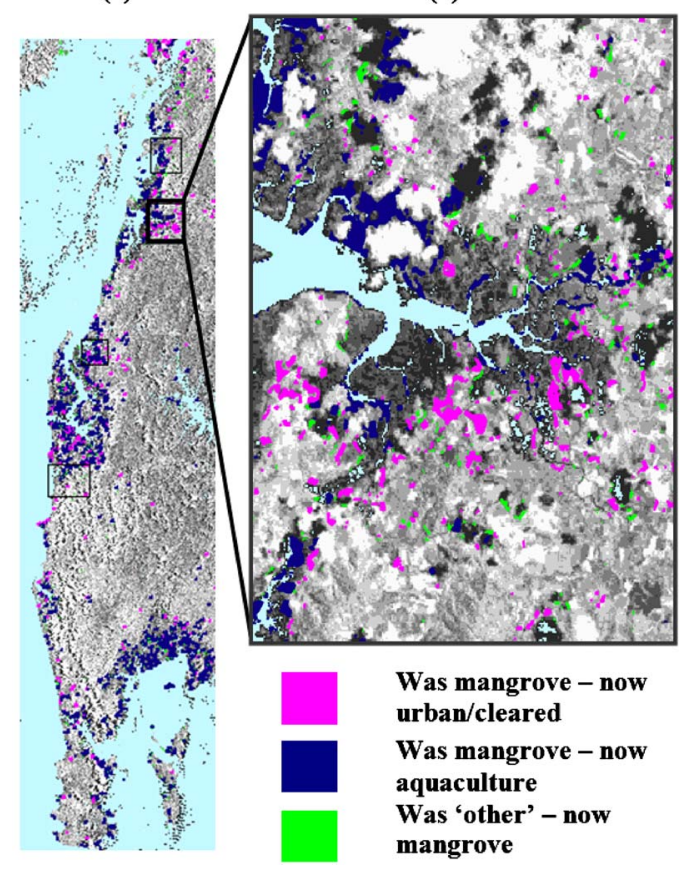

Figure 4. Historic mangrove clearance along the Andaman coast of Thailand, obtained from analysis of a temporal sequence of Landsat TM 5 images.

\section{POSTDISASTER DAMAGE}

From Figure 2, tsunami inundation extent and building damage are key indicators of the postdisaster condition at coastwide and neighborhood scales. Inundation extent was mapped by using a temporal sequence of "before" and "after" Landsat TM 5 imagery (Table 1). An inundation detection methodology was devised on the basis of change in the Normalized Difference Vegetation Index (NDVI) within the near-shore zone. NDVI is a ratio of the near-infrared to red bands and is particularly sensitive to surface scouring, whereby vegetation and urban development is replaced by bare earth and debris. Coastal areas depicted in red (in grayscale: medium gray) in Figure 5 show the coastal regions where inundation caused extreme surface scouring and where accompanying damage to urban development was severe.

At the per-building level, a temporal sequence comprising high-resolution "before" and "after" satellite imagery was used to detect urban damage within four study sites. The study sites were selected on the basis of the criteria described above, together with the availability of high-resolution remote sensing coverage. The imagery comprised both Quickbird and IKONOS data sets, either purchased directly from the vendor or obtained by the National Science Foundation courtesy of the Clearview license. In terms of timeliness, the "after" data for Site 4 were acquired just one week after the tsunami, and as 
COASTAL ECOSYSTEMS AND TSUNAMI PROTECTION AFTER THE DECEMBER 2004 INDIAN OCEAN TSUNAMIS87I

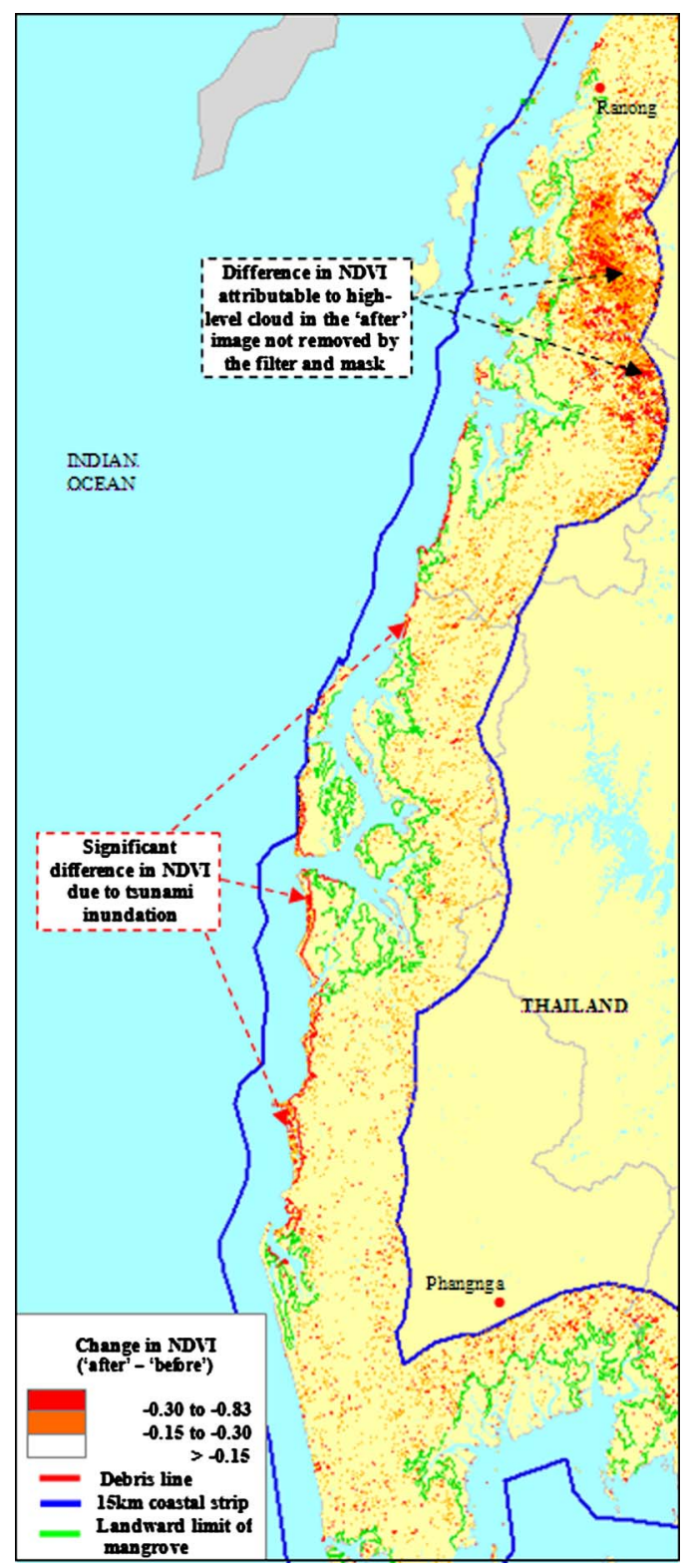

Figure 5. Inundation area and debris line, identified as function of change in NDVI between the Landsat TM 5 "before" and "after" images. Coastal areas in red (in grayscale: medium grey) indicate significant scouring as a result of tsunami impact. 


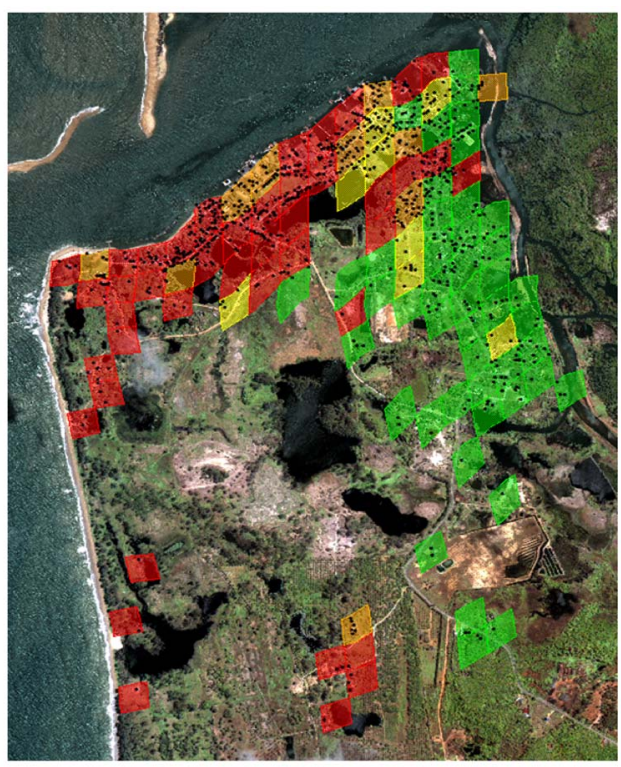

$\%$ collapsed buildings

$\mathbf{8 0 - 1 0 0 \%}$

$50-80 \%$

$30-50 \%$

$0-30 \%$

Figure 6. Damage map for Ban Nam Khem, developed by using high-resolution Quickbird and IKONOS imagery for an urban area at Site 4. The percentage of collapsed buildings is computed within zones at 100-m intervals from the open coast and inlet shores.

such provide an extremely accurate record of damage prior to cleanup operations. The first available imagery for Sites 1-3 is less timely, being collected 1 to 2 months afterward. Preprocessing was conducted to prepare the imagery for visually based damage assessment and field deployment within the VIEWS ${ }^{\mathrm{TM}}$ field data collection and visualization system.

Figure 6 shows an example of the damage map developed for Site 4 through expert interpretation of high-resolution pretsunami and post-tsunami imagery. Of the 761 structures sampled, 449 (59\%) were classified as collapsed, with 312 sustaining less damage. The degree of damage is most extreme bordering the open coast and inlet, where 50 $100 \%$ of the houses were destroyed. The degree of damage captured by the remote sensing coverage rapidly diminishes inland, reaching $0-30 \%$ at a distance of approximately $500 \mathrm{~m}$ from the shorelines. An accuracy assessment conducted for a random sample of 369 buildings within Site 4 suggested an overall classification accuracy of $89.5 \%$ (see also Adams et al. 2005a, b). 
COASTAL ECOSYSTEMS AND TSUNAMI PROTECTION AFTER THE DECEMBER 2004 INDIAN OCEAN TSUNAMIS873

\section{FIELD DATA}

\section{VIEWSTM SYSTEM}

VIEWS $^{\mathrm{TM}}$ is a laptop-based portable field data collection and visualization system used during disaster reconnaissance missions to collect georeferenced data: damage observations, photos, and video footage. The system can be deployed from a moving land vehicle, boat, aircraft, or on foot. Through a real-time GPS feed, the geographic location of every record is overlaid on "before" and "after" remote sensing images and damage base maps. Through built-in GIS functionality, the field team members can also use the high-resolution satellite scenes to prioritize field survey activities, plan and track their route, and pinpoint damaged structures and features of interest. Traditional methods of postdisaster damage assessment typically involve walking surveys, whereby damage indicators together with the overall damage state are logged on a spreadsheet manually. In terms of efficiency, past deployments have indicated that VIEWS ${ }^{\mathrm{TM}}$ significantly increases the rate at which survey data are collected (e.g., Adams et al. 2004c). VIEWS ${ }^{\text {TM }}$ has previously been used in reconnaissance activities after the 2003 Bam, Iran earthquake (Adams et al. 2004b); Hurricane Charley and Hurricane Ivan, which struck the U.S. Gulf Coast in 2004 (Adams et al. 2004a, c); and the 2004 Niigata ken Chuetsu, Japan, earthquake (Huyck et al. 2005).

The Indian Ocean event constitutes the first deployment of VIEWS ${ }^{\mathrm{TM}}$ and highresolution satellite imagery for post-tsunami field reconnaissance (Ghosh et al. 2005). The system was deployed to study Sites 1-4 from 16-25 August 2005, in order to "ground-truth" the preliminary remote sensing results. VIEWS ${ }^{\text {TM }}$ was equipped with satellite base layers, including the Landsat land use classification, the mangrove change/ loss map, and the Quickbird and IKONOS satellite imagery (Table 1). The damage survey of impacted areas (Figure 7) was conducted by a three-member team from a moving land vehicle, on foot, or by boat, depending on vehicular access and type of land use (e.g., mangroves). In general, access to selected study areas did not prove to be a significant limitation.

Fourteen hours of georeferenced digital video were recorded along the reconnaissance survey route, which covered about 75 miles. Of this route, 50 miles were covered from a moving land vehicle, 20 miles from a boat, and 5 miles from a walking tour. A library of approximately 550 digital photos was also collected by the team.

\section{DAMAGE OBSERVATIONS}

To systematize damage observations in the field, we developed a five-point visual damage scale for three key building classes that are typical in the study region: traditional wood housing, concrete-frame housing with infill walls, and large reinforced concrete frame buildings. Each level of damage on the scale was represented by a photo of tsunami damage in this region of Thailand, generally obtained from prior reconnaissance studies. The visual damage scale for the concrete housing class is reproduced in Appen$\operatorname{dix}$ A. Using this damage observation instrument was advantageous for ensuring data quality: it facilitated rapid data collection in the field, standardized the damage ratings between observers, and helped the field team communicate with local residents (across 


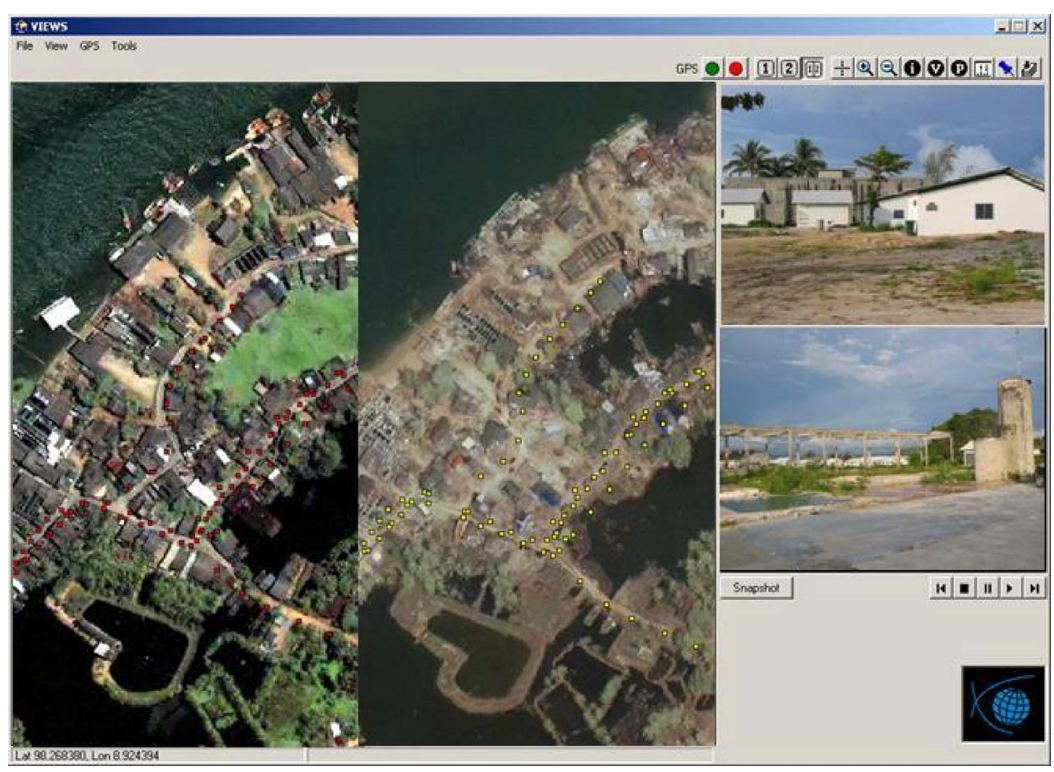

Figure 7. VIEWS of the GPS route (illustrated by the small circles) followed by the field team in Ban Nam Khem (Site 4). The photo in the upper right shows an example of the rapid reconstruction that is occurring, and the digital video in the lower right shows remaining building damage.

potential language, literacy, and educational barriers) who were able to corroborate, correct, or elaborate upon the team's observations. Verbal damage scales were also developed for other types of nonbuilding damage (Appendix A) and also helped to systematize these observations.

The visual and verbal damage scales were designed to be consistent with previously published tsunami intensity scales such as the 6-level Sieberg-Ambraseys scale (Ambraseys 1962) and the 12-level intensity scale by Papadopoulos and Imamura (2001). These scales are similar to the more familiar Modified Mercalli Index (MMI) for earthquake shaking intensity. We were thus able to systematically use our field observations of damage to characterize tsunami damage intensity for different villages and different locations within these villages.

Table 2 shows the correlation between village location relative to mangroves and tsunami damage intensity for the eight villages we surveyed at Site A. These villages are located within a fairly short distance of one another. Damage observations for concrete housing and other structural types, measured according to the scales discussed above, were used to classify each village according to the Papadopoulos and Imamura tsunami intensity scale, which varies from I ("not felt") to XII ("completely devastating"). All of the exposed villages suffered severe building destruction, whereas communities established behind mangrove forests sustained minimal damage. In one village where only a portion of the village was protected by mangroves, that portion suffered little damage, while the exposed portion was devastated. 
COASTAL ECOSYSTEMS AND TSUNAMI PROTECTION AFTER THE DECEMBER 2004 INDIAN OCEAN TSUNAMIS875

Table 2. Tsunami intensity and damage at Site A

\begin{tabular}{|c|c|c|c|c|}
\hline \multirow{2}{*}{$\begin{array}{l}\text { Location relative } \\
\text { to mangroves }\end{array}$} & \multirow[b]{2}{*}{ Village } & \multicolumn{3}{|c|}{ Tsunami damage intensity } \\
\hline & & $\mathrm{V}$ & VIII & XI \\
\hline \multirow{4}{*}{ Exposed } & Tap Nya & & & $\times$ \\
\hline & Ban Talay Nok & & & $\times$ \\
\hline & Ban Kluai Nok & & & $\times$ \\
\hline & Triam & & & $\times$ \\
\hline \multirow[t]{2}{*}{ Partly exposed } & Village 7 & & $\times$ & \\
\hline & Ta Klang & $x$ & & \\
\hline \multirow[t]{2}{*}{ Behind mangroves } & North of village 4 & $x$ & & \\
\hline & Pak Triam & $\times$ & & \\
\hline \multicolumn{5}{|c|}{$\begin{array}{l}\text { a Based on the 12-point Papadopoulos and Imamura scale, from which partial defini- } \\
\text { tions are abstracted in the three footnotes below. } \\
\text { b "V= Strong - many small vessels move strongly onshore, few of them crash into each } \\
\text { other or overturn; traces of sand layer left behind on ground with favorable conditions." } \\
\text { " "VIII= Heavily damaging - most small vessels are damaged, many are washed away, } \\
\text { few large vessels are moved ashore or crash into each other; big objects are drifted } \\
\text { away; erosion and littering on beach; extensive flooding; most wooden structures are } \\
\text { washed away or demolished, damage of grade } 2 \text { in a few masonry buildings." } \\
\text { " "XI=Devastating--water backwash drifts cars and other objects in the sea; big boul- } \\
\text { ders from the sea bottom are moved inland; damage of grade } 5 \text { in many masonry build- } \\
\text { ings." }\end{array}$} \\
\hline
\end{tabular}

\section{INTERVIEW DATA}

Field work on the environmental management portion of the study, which focused on gathering interview data, was conducted over the same period and in many of the same locations as the previously described field work on the biophysical portion of the study.

\section{CONCEPTUAL FRAMEWORK}

We offer two alternative hypotheses premised on the concepts of social capital and institutional design of external aid interventions. First, we hypothesized that variation in local performance related to civic actions for mangrove conservation is explained solely by social capital. Social capital is described by Putnam (1995) as "features of social organization such as networks, norms and social trust that facilitate coordination and cooperation for mutual benefit." The level of social capital affects community performance in multiple societal domains like environmental conservation, economic development, and crime. Two key conditions of social capital are that participation in organizations must be voluntary and that efforts to organize are internal to a village. Villages with high social capital are better able to restrain individual opportunism and act collectively for mutual benefit (Putnam, et al. 1993) — as in the case of mangrove conservation.

Second, we hypothesized that the influence of social capital on village performance is mediated by the design of external aid programs. The effectiveness of the institutional 
design of aid delivery programs is expected to be as important as the level of social capital for explaining performance. Aid delivery initiatives are particularly influential during the aftermath of disasters. Compared with predisaster conditions, humanitarian aid delivery organizations are more active and influential in local decision making and actions (Berke and Beatley 1997). Bottom-up external aid delivery programs facilitate and enable social capital to be brought to bear across multiple social domains. Top-down aid delivery denies grassroots-level networks the opportunity to respond to local needs, and it can weaken social networks and increase dependence on outside assistance.

\section{INTERVIEWS}

The mangrove ecosystem management phase of the study entailed an evaluation of six villages in Ranong province. The villages were in Sites 1, 2, and A (Figure 1) and were selected on the basis of two criteria: sustained damage to the built environment, and significant mangrove forest ecosystems within or adjacent to village boundaries (Ranong is one of the few remaining provinces in Thailand with relatively healthy mangrove forests). During 16-23 August 2005, semistructured interviews were conducted with 11 local "key informants." We considered such informants to be individuals who are knowledgeable and influential about disaster recovery and mangrove management practices in the six villages.

An interview protocol was adapted from the World Bank's Social Capital Assessment Tool (SOCAT) (World Bank Group 2004). The protocol included a limited version of SOCAT that consisted of two sets of questions. The first set was derived to gauge village performance in mangrove protection. The second set aimed to determine the level of social capital in the form of grassroots networks, trust, and reciprocity among local people (Putnam 1995, Putnam et al. 1993) and to examine external aid delivery programs and how they affected the village's performance (Berke and Beatley 1997). To supplement the interviews, field observations were undertaken to verify the mangrove conditions and the protection and restoration practices. The protocol is reproduced in Appendix B.

\section{PRELIMINARY FINDINGS}

We report two sets of preliminary observations. As indicated in the interview questions in Appendix B, one set involves village performance in mangrove conservation. A second set focuses on the level of social capital and design of external aid delivery systems and on how these factors affect performance. We offer preliminary evidence that answers the research hypotheses related to how social capital and formal external aid organizations affect village performance.

\section{Village Performance in Mangrove Conservation}

Village performance in mangrove conservation and reforestation efforts varied across the six villages. The highest-performing village, Tha Yang, adopted appropriation rules that permitted limited tree cutting, provided that wood products were for personal use and not for commercial purposes. A village committee was organized to ensure compliance with the rules and monitor the overall ecological health of the reforested sites. A robust mangrove replanting program was also established. 
COASTAL ECOSYSTEMS AND TSUNAMI PROTECTION AFTER THE DECEMBER 2004 INDIAN OCEAN TSUNAMIS877

The remaining five villages showed considerable variation in performance. Three villages, Had Sai Khao, Had Prapad, and Ao Kuey, had a moderate level of conservation effort. Interviewees varied in their assessments about the overall performance of community restoration and reforestation efforts. Although these villages adopted replanting activities, all fell short of adopting a level of initiatives equivalent to Tha Yang. In contrast, the villages of Had Sai Dam and Tha Chang had a low level of performance in mangrove conservation programs. Interviews revealed that villagers considered mangrove conservation to be the responsibility of the Mangrove Forest Conservation Unit (MFCU) of the Royal Thai Department of Forestry.

\section{Social Capital}

Our preliminary findings suggest that four villages have a high level of social capital. Interviews revealed that social capital is present in a variety of forms, including mangrove conservation groups that were established before the tsunami. In these villages, several community groups evolved after the tsunami, particularly fisheries groups - such as fish cage culture groups and fishing gear groups - and women's groups to promote additional income activities, such as fish sauce making, batik painting, cooking, and saving money. In general, all informants in these villages regarded their villages as having satisfactory cooperation. Community leaders were highly respected, and community members were willing to help each other after the tsunami in activities such as retrieving gear and recovering boats. One interviewee mentioned the sharing of fish catches. Collective problem-solving and decision-making processes were the norm, and there were generally few conflicts. An exception was found in Ao Kuey, where both informants indicated inequality concerning aid distribution, which might have caused mistrust and conflicts to arise after the tsunami. Another village, Tha Chang, also had a moderate level of social capital, as the villagers exhibited generally less interest in mangrove conservation and other collective actions.

\section{External Aid Delivery}

One village had external aid delivery programs that provided a high level of support for multiple disaster recovery domains, three villages had moderate support, and two experienced low support. The village with highly supportive external aid, Tha Yang, received support for mangrove replanting efforts from a Japanese donor organization (OISCA), as well as external aid disaster recovery programs that were bottom-up in orientation. OISCA, for instance, started the mangrove conservation project and provided seedlings and funding to support the replanting phase. Continued funding was conditional, however, based on the interests and commitment shown by community members. This seemed to have initiated a standalone community group specifically established to protect mangroves.

Three villages had moderate levels of external support, in that all received financial assistance and seedlings from the same external aid organization (OISCA), but all had experience with disaster aid that was top-down. Interviews revealed numerous forms of top-down aid delivery systems, and many interviewees noted that the type of aid and help did not always match the needs - this was due largely to the lack of consultation 
with villagers. The most contentious example was related to the housing reconstruction program by the Thai military. The government used its military to build new two-story houses, on stilts, which are not suitable for the people and the weather conditions. For example, the houses did not seem sturdy enough to withstand the wind, and the style was not appropriate for the rain. Other issues raised by several informants concerning external aid were related to unfair distribution of aid and inequality in treatment. In other cases, there were several organizations operating in the same areas, at times resulting in some conflicts. There was some mention that aid from one agency was withdrawn when it learned that another agency was in the area. Finally, Had Sai Dam and Tha Chang experienced relatively low levels of external aid; for example, OISCA did not provide aid for replanting, and most other aid delivery programs were top-down.

\section{Influence of Social Capital and External Aid on Village Conservation Performance}

While our findings are preliminary, several patterns emerged concerning the influence of social capital and external aid programs on village performance in conservation. Overall, the findings suggest that external aid may be related to conservation performance, but the relationship may also be interactive with social capital. Three specific observations can be made. First, social capital is not clearly and consistently related to mangrove conservation performance. While social capital remains high in four of the villages, there appears to be considerable fluctuation in conservation performance, because villages with high levels of social capital varied in exhibiting low or high levels of conservation efforts. Second, conservation performance and external aid may have a close relationship as top-down aid delivery programs have an independent negative influence on performance. In all cases, the level of support from external aid organizations matched the level of performance in conservation (i.e., if aid was bottom-up, then performance was high, and if aid was top-down, then performance was low). Third, it could also be that when both social capital and external aid are considered jointly, the interaction may have a strong positive influence on performance. Evidence from our interviews suggests that, in villages with high levels of social capital, it appears that performance drops as a result of external disaster recovery aid programs that deny grassrootslevel networks the opportunities to respond to local needs. This process may weaken social capital and suppress local initiatives aimed at mangrove conservation. Although external aid from OISCA was bottom-up and supported mangrove conservation efforts, the potential influence of this external aid program is reduced when aid for other disaster recovery domains (notably housing reconstruction) prevents activation of social capital. We think the relationships developed by external aid programs in one domain of disaster recovery are generalized across multiple domains.

\section{CONCLUSIONS}

This study has adopted an interdisciplinary, mixed-methods approach to address the role of coastal ecosystems in tsunami protection. In our case study of mangrove forests in Thailand, we address the issue from both a biophysical and a management perspective. Toward this end, we have gathered such diverse data as satellite imagery, georeferenced video imagery, photos, field observations, and key-informant interview responses. 
COASTAL ECOSYSTEMS AND TSUNAMI PROTECTION AFTER THE DECEMBER 2004 INDIAN OCEAN TSUNAMIS879

We have also developed and pilot-tested methods for analyzing the data. It should be noted that this is a very specific, exploratory study of linkages between biophysical and management-related variables.

The study to date suggests several preliminary conclusions in terms of methodology. First, remote sensing analysis is a powerful tool for studies of natural disasters. Its utility is not limited to postdisaster assessment of damage, but extends also to characterizing certain conditions of predisaster vulnerability (in this case, predisaster changes in the presence of mangroves). Second, integrating remote sensing analysis and field observation greatly enhances the research value that either method could have provided alone. For example, satellite imagery can help to systematically identify potential locations for field study. It can, in the context of portable data collection systems such as VIEWS ${ }^{\text {TM}}$, provide invaluable spatially referenced information to researchers in the field. Conversely, it is crucial to verify, validate, and supplement remote sensing analysis with field data. For example, high-resolution satellite images provide a reasonable basis for identifying collapsed buildings but not moderately damaged buildings. Third, gathering both quantitative/visual data and qualitative data (e.g., from interviews) is also highly beneficial. In this case, in order to understand the role of mangroves in protection from natural hazards, it is important to gain information about both the buffering capacity of mangroves and about factors that influence mangrove conservation or degradation.

Preliminary analysis of our data suggests several findings. First, while they are only one of many factors that influenced tsunami damage intensity, mangroves do appear to have been an effective buffer against tsunami forces. Villages that were behind substantial mangrove forests suffered relatively little damage, while otherwise comparable villages that were not so protected were devastated. The extent to which this finding can be generalized from our study area to other regions remains to be investigated.

Second, we found considerable variation in the performance of local conservation efforts across villages. Performance appears to be influenced by the design of external aid programs (higher performance levels result from more bottom-up-oriented programs). However, social capital does not have a consistent influence on performance. Alternatively, social capital does appear to matter when external aid programs are bottom-up-oriented, because they enable and facilitate villages' application of their social capital. Consequently, to be effective, external aid programs should draw on local social capital rather than deny its presence. Staff personnel in external aid organizations should view a disaster as providing a window of opportunity to enable and build relationships with local people that allow them to become active participants.

What are the future research needs? In the short run, we will be undertaking systematic analysis of the data collected. This includes (1) conducting accuracy assessments according to the methodology proposed by Maingi et al. (2002) on land use classification and conducting damage assessments derived from remote sensing analysis, (2) refining the analytical methods, (3) more thoroughly analyzing damage patterns, and (4) more systematically testing the hypothesis that mangroves helped protect villages and reduce tsunami losses. The data analysis also includes coding procedures and content analyses of our interview data. We plan to more thoroughly test the relationships among 
village conservation performance, social capital, and external aid. The flexibility of our case study methodology allows for other factors to emerge as potential predictors of performance.

In the long run, we maintain that priority should be given to disaster research that emphasizes multiple case research designs, with each case using the same methods and variables to ensure comparability. Our analysis of local performance in mangrove conservation uses a few villages as case studies, which are sufficient for a pilot study but too few for a definitive analysis. Our findings should be viewed with caution, since we are limited in testing the independent effects of social capital and external aid on performance. Research suggests an additional number of possible causal factors. Krishna (2002), for example, outlines a complete and useful discussion of the various competing explanations of how social capital explains local institutional performance. A larger number of case studies than examined here would be required for a similar comprehensive explanation.

Similarly, multiple cases are important for developing more generalized lessons regarding the protective capacity of coastal ecosystems. The methods developed for identifying predisaster coastal ecosystem change, characterizing damage patterns, and isolating the effect of mangroves can be applied to other regions affected by the tsunami. For example, our study region can be compared with others that experienced much greater predisaster loss of mangroves (e.g., some areas of southern India), are protected by other types of coastal landscapes (e.g., sand dunes in Sri Lanka), or were subject to much greater tsunami forces (e.g., Indonesia). The tragic magnitude of the 2004 Indian Ocean tsunami affords a unique opportunity for comparative study about hazard mitigation that should not be wasted.

\section{ACKNOWLEDGMENTS}

This study was supported primarily by the National Science Foundation (NSF) through its Small Grants for Exploratory Research program under grant number SES0522963. It was also supported in part by NSF's Earthquake Engineering Research Centers Program under NSF Award number EEC-9701471 and by the Canada Foundation for Innovation under project number 201867. J. Alder was supported by the Sea Around Us Project. Remote sensing imagery was provided courtesy of GISTDA, the U.S Geological Survey, DigitalGlobe, Space Imaging, and the Pacific Disaster Center (PDC) through the ClearView license. The authors thank William Rees at the University of British Columbia and Harry Yeh at Oregon State University for technical input, as well as many researchers and support staff in Thailand for their invaluable assistance in the field, including Professor and Director Kungwan Juntarashote, Dr. Methee Kaewnern, and research assistants Montri Mongkala, Ilada Neamthed, and Pisuttipong Suriyakaan at the Coastal Development Centre, Kasetstart University; Mr. Sompoch Nimsantijaroen and others at the Ranong Coastal Resource Research Station; Kareemy from Ban Nam Khem; and Mr. Kittipat Larpchurat at the Mangrove Restoration Centre in Kuraburi. The seven coauthors contributed equally to this paper. 


\section{Visual Damage Scale}
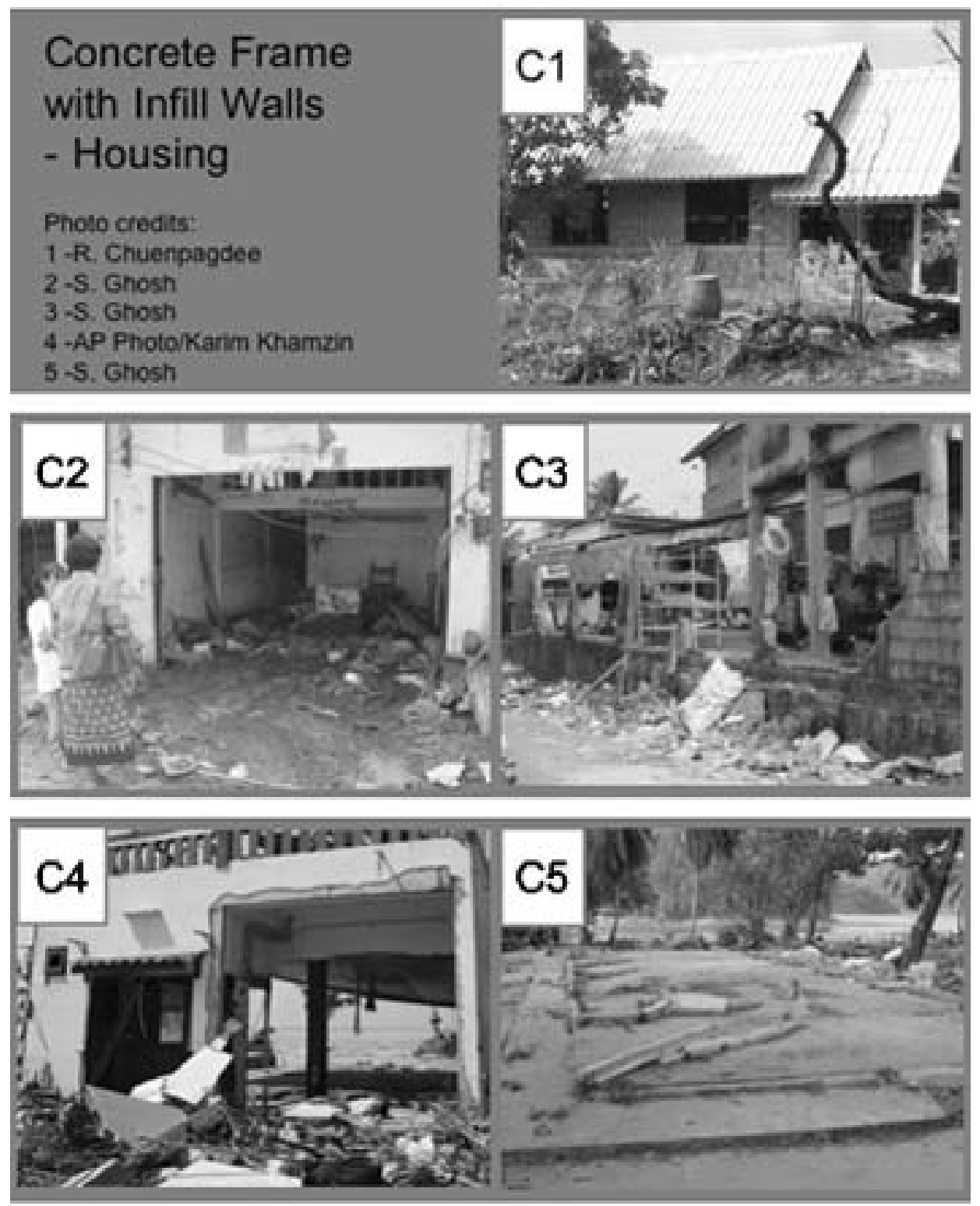

Figure A1. Visual damage scale for concrete housing. 
- Housing damage

...by construction type and severity (see visual damage scale)

- Small boats

B1 - remained in water

B2 - a few moved slightly onshore

B3 - many moved strongly onshore; a few crashed or overturned

B4 - most moved violently onshore, crash, or overturn

B5 - many damaged

B6 - most damaged, many washed away

B7 - most destroyed or washed away

- Large boats

$S 1$-remained in water

S2 - few moved ashore or crash into each other

S3 - many moved violently ashore; few are destroyed

S4 - most moved violently as hore; many destroyed or collide with buildings

- Sand and other deposits

D1 - no sand layer

D2 - traces of sand layer

D3 - sand layer and accumulations of pebbles

D4 - erosion and littering on beach

D5 - extensive erosion and littering on beach; local ground subsidence

D6 - small boulders from sea moved inland; extensive ground subsidence

D7 - big boulders from sea bottom moved inland

- Land objects moved

O1 - objects not moved

$\mathrm{O} 2$ - objects of variable size and stability overturn and drift

O3 - big objects drift away

O4 - cars overturned and drifted

O5 - water backwash drifts cars and other objects into the sea

- Artificial embankments

E1 - no damage

E2 - slight damage

E3 - embankments collapse

- Utility poles

P1 - no damage

P2 - bent

P3 - broken

- Mangrove damage

M1 - no damage

M2 - slight damage

M3 - partial des truction

M4 - extensive destruction

M5 - complete destruction

Figure A2. Verbal damage scales. 
COASTAL ECOSYSTEMS AND TSUNAMI PROTECTION AFTER THE DECEMBER 2004 INDIAN OCEAN TSUNAMIS883

\section{APPENDIX B: INTERVIEW PROTOCOL FOR SOCIAL CAPITAL ASSESSMENT}

\section{Coastal Mangroves General Information}

1.1 What is the size of the mangrove forest in your community (hectares)?

1.2 Identify all important goods and services of the mangrove forest that benefit the community.

If possible, ask respondent to refer to a map to locate salient features.

Tsunami hazard mitigation (reduces wave runup and velocity)

Fishery

Wood products

Wastewater treatment

Other

Ask respondent to comment about the importance of these goods/services.

1.3 During the last decade, has there been any change in the integrity (health) of the mangrove forest? Has the health improved or declined?

1.3a If change has occurred, what are the reasons for the change?

1.3b Have these changes accelerated since the December 2004 tsunami disaster? If yes, why have they accelerated?

1.4 Who owns the mangrove forest?

Government (national, regional, local)

Private individual or family

Private corporation

Cooperative

The community

Other

1.5 Are there regulations to protect the mangrove forest?

Limit use of coastal hardening structures (levees, seawalls, etc.)

Rules for avoidance of development in ecologically sensitive areas

Resource appropriation rules that limit shrimp, fish, vegetation harvesting

Pollution prevention

Replanting requirements

Cutting mangroves for charcoal Other

1.5a What organizations have management and enforcement responsibilities? To what extent are these regulations effective and enforced?

1.6 How can the rules and enforcement be improved?

\section{Community-Based Social Capital}

This set of questions is useful in getting respondents to focus on collective action and solidarity on specific cases in which the community worked collectively to resolve issues, whether or not the outcomes were positive. The interviewer probes for specific instances of collective action undertaken since the tsunami disaster. Respondents are also probed to focus on an issue tied to coastal mangroves. The cases 
should be representative of the level of collective action in the community. The extent to which a community is able to come together to address issues of common importance is an important indicator of social capital.

2.1 People from the same community often get together to address a particular issue that faces the community, fix a problem, improve the quality of life, or something similar. Which of the following issues has your community tried to address after the tsunami disaster?

(Probe: reconstruction of housing that destroyed a wetland or mangrove forest, recovery of a fishery or agriculture industry, loss of tourism, debris removal in sensitive ecological areas, pollution, standing water/stagnation)

2.2 Have there been efforts by the community to improve the quality of coastal mangrove forests? Can you describe one instance that is most representative of how the community deals with coastal ecosystems in detail? Were there community groups that played an important role? What kinds of responses did you get from the local government? From other organizations? From the rest of the community? What kinds of obstacles did you have to deal with? What was the outcome of the effort?

(Probe for locus of leadership, resources tapped, sources of resistance, who benefited or suffered from the outcome, the kind of follow-up that occurred as a result of the effort, and the mechanisms employed to ensure sustainability of the effort.)

2.3 Has this community ever attempted to make improvements but failed? Why do you think the attempt failed? What would you have done differently to make the effort more successful?

(Probe for constraints on collective action; identify roles of government, community organizations, and NGOs in influencing outcomes; and discuss the relationship between the community, representative organizations, local government, and other civil society actors.)

\section{Community Organizations}

3.1 What are the groups, organizations, or associations that function in this community on issues involving the development, use, protection, and restoration of coastal mangroves?

(Probe: have the respondents list all the organizations, formal and informal, that exist in the community or part of a national or international network. Ask which organizations have emerged since the tsunami.)

3.2 Which groups play the most active role in helping improve the well-being of the coastal mangroves?

3.3 How did these most active groups or organizations get started (government initiated, through government donations, NGO donations, grassroots initiative, etc.)? What year did they get started?

3.4 Of the organizations on the list created from Q 3.1, which ones are most important and accessible to the community? Which ones are less accessible?

3.5 How are the leaders selected (election, appointment, inheritance)? How stable 
COASTAL ECOSYSTEMS AND TSUNAMI PROTECTION AFTER THE DECEMBER 2004 INDIAN OCEAN TSUNAMIS885

is the leadership (frequent sudden changes, normal progressive change, or never changes)? Is the leadership generally harmonious or collective?

3.6 Which organizations from Q 3.1 are effective in working together? How do they work together (hierarchically, collaboratively)?

3.7 Are there any organizations that work against each other (compete or conflict)?

3.8 Some groups may share the same members, and some groups have different members. Which organizations have the same or similar memberships?

3.9 Are there organizations that share resources?

\section{REFERENCES}

Adams, B. J., Huyck, C. K., Mio, M. Z., Cho, S., Eguchi, R. T., Womble, A. J., and Mehta, K., 2004a. Streamlining post-disaster data collection and damage assessment, using VIEWS (visualizing impacts of earthquakes with satellites) and VRS (virtual reconnaissance system), in Proceedings of 2nd International Workshop on Remote Sensing for Post-Disaster Response, Newport Beach, Calif. http://mceer.buffalo.edu/publications/workshop/05-SP03/ 203_b_adams_paper.pdf

Adams, B. J., Huyck, C. K., Mio, M., Cho, S., Ghosh, S., Chung, H., Eguchi, R. T., Houshmand, B., Shinozuka, M., and Mansouri, B., 2004b. The Bam (Iran) earthquake of December 26, 2003: Preliminary reconnaissance using remotely sensed data and the VIEWS system. http://mceer.buffalo.edu/research/Bam/bam.pdf

Adams, B. J., Womble, J. A., Mio, M. Z., and Mehta, K., 2004c. Collection of satellite referenced building damage information in the aftermath of Hurricane Charley, MCEER Quick Response Report Series, accessed September 30. http://mceer.buffalo.edu/research/ Reconnaissance/Charley8-13-04/04-SP04.pdf

Adams, B. J., Ghosh, S., Wabnitz, C., and Alder, J., 2005a. Post-tsunami urban damage assessment in Thailand, using optical satellite imagery and the VIEWS ${ }^{\mathrm{TM}}$ field reconnaissance system, in Proceedings, 250th Anniversary of the 1755 Lisbon Earthquake, Lisbon, Portugal.

Adams, B. J., Wabnitz, C., Ghosh, S., Alder, J., Chuenpagdee, R., Chang., S. E., Berke, P. R., and Rees, W. E., 2005b. Application of Landsat 5 and high-resolution optical satellite imagery to investigate urban tsunami damage in Thailand as a function of pre-tsunami environmental degradation, in Proceedings, Third International Workshop on Remote Sensing for Disaster Response, Chiba, Japan. http://ares.tu.chiba-u.jp/workshop/Chiba-RS2005/ Paper\%20Adams.pdf

Ambraseys, N. N., 1962. Data for the investigation of the seismic waves in the eastern Mediterranean, Bull. Seismol. Soc. Am. 52, 895-913.

Berke, P., and Beatley, T., 1997. After the Hurricane: Linking Recovery to Sustainable Development in the Caribbean, Johns Hopkins University Press, Baltimore, MD, 232 pp.

Dahdouh-Guebas, F., Jayatissa, L. P., Di Nitto, D., Bosire, J. O., Lo Seen, D., and Koedam, N., 2005. How effective were mangroves as a defence against the recent tsunami? Curr. Biol. 15 (12), R443-R447.

Dengler, L., and Preuss, J., 1998. Mitigation lessons from the July 17, 1998 Papua New Guinea tsunami, Pure Appl. Geophys. 160, 2001-2031. 
FAO, 2005. Tsunami mitigation by mangroves and coastal forests, accessed May 27. www.fao.org/forestry/foris/webview/pageview.jsp?pageId=31843\&langId=1

Fast, A. W., and Menasveta, P., 2003. Mangrove forest recovery in Thailand, Bull. Pol. Acad. Sci. Chem. 34 (3), 6-9.

Ghosh, S., Huyck, C. K., Adams, B. J., Eguchi, R. T., Yamazaki, F., and Matsuoka, M., 2005. Preliminary field report: Post-tsunami urban damage survey in Thailand, using the VIEWS reconnaissance system, accessed September 30. http://mceer.buffalo.edu/research/tsunami/ page1.asp

Harada, K., and Imamura, F., 2003. Study on the evaluation of tsunami reducing by coastal control forest for actual conditions, Asia and Pacific Coasts 2003, in Proceedings, Second International Conference, Makuhari, Japan.

Hiraishi, T., and Harada, K., 2003. Greenbelt tsunami prevention in South Pacific region, Report of the Port and Airport Research Institute 42 (2), 1-23.

Huyck, C., Scawthorn, C., Bardet, J.-P., Kayen, R., Kawamata, Y., Olshansky, R., Somerville, P., Mori, J., Rathje, E., Bay, J., Jibson, R., Kelson, K., Pack, R., and Nishi, N., 2005. Preliminary observations on the Niigata Ken Chuetsu, Japan, earthquake of October 23, 2004, EERI Newsletter 39 (1).

Krishna, A., 2002. Active Social Capital: Tracing the Roots of Development and Democracy, Columbia University Press, New York, NY, 192 pp.

Maingi, J. K., Marsh, S. E., Kepner, W. G., and Edmonds, C. M., 2002. An accuracy assessment of 1992 Landsat-MSS derived land cover for the Upper San Pedro watershed (U. S./Mexico), (EPA/600/R-02/040), U.S. Environmental Protection Agency, accessed August 15. http:// www.epa.gov/nerlesd1/land-sci/pdf/epa600r02040.pdf

Pacific Marine Environmental Laboratory (PMEL), National Oceanic and Atmospheric Administration (NOAA), 2005. Tsunami event-26 December 2004, accessed May 18. www.pmel.noaa.gov/tsunami/indo_1204.html

Papadopoulos, G. A., and Imamura, F., 2001. A proposal for a new tsunami intensity scale, ITS 2001 Proceedings, Session 5, Number 5-1.

Putnam, R., Leonardi, R., and Nanetti, R., 1993. Making Democracy Work: Civic Traditions in Modern Italy, Princeton University Press, Princeton, NJ, $280 \mathrm{pp}$.

Putnam, R., 1995. Bowling alone: America's declining social capital, J. Democracy 6 (1), 65 78.

Research Group on the December 26, 2004 Earthquake Tsunami Disaster of Indian Ocean, 2005. Field survey result of Thailand, accessed May 13. Measured tsunami heights from 2nd field survey of Thailand, accessed May 13. http://www.drs.dpri.kyoto-u.ac.jp/sumatra/indexe.html

Synolakis, C., 2002. Tsunami and seiche, in Earthquake Engineering Handbook, Chen, W.-F., and Scawthorn, C. (eds.), CRC Press, Boca Raton, FL.

Titov, V. V., 2005. Personal communication, July 22.

UNEP, 2005. National rapid environmental assessment: Thailand, accessed August 10. http:// www.unep.org/tsunami/reports/TSUNAMI_THAILAND_LAYOUT.pdf

Wetlands International, 2005a. Natural Mitigation of Natural Disasters, Assessment report to Ramsar STRP12, accessed June 15. http://www.wetlands.org/tsunami/

Wetlands International, 2005b. Rapid country level assessment, accessed September 5. http:// www.wetlands.org/Tsunami/Tsunamidata.htm 
COASTAL ECOSYSTEMS AND TSUNAMI PROTECTION AFTER THE DECEMBER 2004 INDIAN OCEAN TSUNAMIS887

World Bank Group, 2004. Social Capital Assessment Tool (SOCAT): A Toolkit for Understanding and Measuring Social Capital and Its Role in Development, World Bank Group, Washington, DC.

(Received 3 October 2005; accepted 12 April 2006) 